\title{
Fabrication of stable, low optical loss rib-waveguides via embossing of sputtered chalcogenide glass-film on glass-chip
}

\author{
Nabil Sayed Abdel-Moneim • Christopher J. Mellor • \\ Trevor M. Benson · David Furniss • Angela B. Seddon
}

Received: 13 November 2013 / Accepted: 17 March 2014 / Published online: 17 April 2014

(C) The Author(s) 2014. This article is published with open access at Springerlink.com

\begin{abstract}
We report low-loss, single-mode rib optical waveguides on-chip, fabricated using hot-embossing for the first time of radio-frequency sputtered $\mathrm{As}_{2} \mathrm{Se}_{3}$ chalcogenide-glass thin films on a chalcogenide-glass substrate. Waveguides $4-6 \mu \mathrm{m}$ wide and $1.9 \pm 0.1 \mu \mathrm{m}$ high are fabricated. Waveguide optical loss, using the Fabry-Perot technique, which is known to over-estimate loss, is found to be $<0.78 \mathrm{~dB} \mathrm{~cm}^{-1}$ for the TE mode, and $<0.81 \mathrm{~dB} \mathrm{~cm}^{-1}$ for the TM mode, at $1,550 \mathrm{~nm}$ wavelength. Glass stability of the chalcogenide rib waveguides is excellent and is discussed in relation to the results of others.
\end{abstract}

Keywords Chalcogenide-glasses · Planar-waveguides · Integrated-optics · Hot-embossing $\cdot$ RF-sputtering

\section{Introduction}

Molecular species exhibit characteristic vibrational absorption bands in the mid-infrared (IR) region of the electromagnetic spectrum (3-25 $\mu$ m wavelength) (Seddon 2011). Mid-IR integrated-optic chip devices should be developed to take advantage of this for achieving chemical and bio-sensing of molecular species. As pointed out by Tsay et al. (2010), smallfootprint molecular sensors have the potential to bring about low-cost, widely-accessible health and environmental monitoring. Chalcogenide glasses exhibit transparent windows occurring within the range from the visible (e.g. from $500 \mathrm{~nm}$ for $\mathrm{As}_{40} \mathrm{~S}_{60}$ (at.\% hereforwards) to the mid-IR (e.g. to $\sim 20 \mu \mathrm{m}$ for glasses based on $\mathrm{Ge}-\mathrm{As}-\mathrm{Se}-\mathrm{Te}$ ) and passive mono-mode rib waveguides of high numerical aperture (NA) have been demonstrated (Pan

N. S. Abdel-Moneim · T. M. Benson $(\varangle) \cdot$ D. Furniss · A. B. Seddon Faculty of Engineering, George Green Institute for Electromagnetics Research, University of Nottingham, University Park, Nottingham NG7 2RD, UK

e-mail: trevor.benson@nottingham.ac.uk

C. J. Mellor

School of Physics and Astronomy, University of Nottingham,

University Park, Nottingham NG7 2RD, UK 
et al. 2007, 2008; Lian et al. 2009; Seddon et al. 2006), paving the way for miniaturization of photonic chip devices such as mid-IR sensors.

As a first step we have been investigating fabrication of chalcogenide glass waveguides using hot-embossing (also known as nano-imprinting) processing which is potentially fast, cheap and scalable. Hot-embossing is conceptually straightforward: (usually)-flat glass is heated above its glass transition $\left(\mathrm{T}_{\mathrm{g}}\right.$ ), pressed against a mould and, on cooling below $\mathrm{T}_{\mathrm{g}}$ to ambient, the mould imprint is retained in the glass surface. Using a hard, silicon mould, mouldfidelity of hot-embossed chalcogenide glasses has been demonstrated to be at least $\pm 30 \mathrm{~nm}$ (Pan et al. 2007; Seddon et al. 2006). Chalcogenide-glass mono-mode rib waveguides have been fabricated by means of hot-embossing using a hard silicon mould firstly in a one-step 'fibre-on-glass' approach involving two types of chalcogenide glasses (waveguide comprising: over-clad./core/under-clad. of air/As $40 \mathrm{Se}_{60} / \mathrm{Ge}_{17} \mathrm{As}_{18} \mathrm{Se}_{65}$ (at.\%); core: $5 \mu \mathrm{m}$ wide and $1.7 \mu \mathrm{m}$ deep; optical loss: $2.2 \mathrm{~dB} \mathrm{~cm}^{-1}$ at $1,550 \mathrm{~nm}$ wavelength) (Pan et al. 2008) and secondly of a thermally evaporated chalcogenide glass film on a chalcogenide glass substrate (Lian et al. 2009) (comprising over-clad./core/under-clad. of air/As $40 \mathrm{Se}_{60} / \mathrm{Ge}_{17} \mathrm{As}_{18} \mathrm{Se}_{65}$; core: $5.5 \mu \mathrm{m}$ wide and $1.9 \mu \mathrm{m}$ deep; optical loss: $2.9 \mathrm{~dB} \mathrm{~cm}^{-1}$ at $1,550 \mathrm{~nm}$ ). Thermal evaporation is a common thin film deposition technique whereby the source material to be evaporated is placed in a boat and connected to a power supply for heating. The chamber containing the target and the substrate is then evacuated. When the target is heated to a certain temperature, evaporated atoms are transferred from the target allowing them to condense on the cooler substrate surface. Advantages of this technique include a relatively high deposition speed, but thermal evaporation can have difficulties in depositing materials with high melting points as well as multi-component and/or composite materials with a large melting point difference between their constituents, where non-congruent evaporation usually occurs resulting in non-homogeneous films (Seddon 2005). Zakery and Elliott (2007) explain that the thermal evaporation method is not suitable for the accurate transfer of stoichiometry of multi-component glass films; this will be discussed further in Sect. 4. The refractive indices of $\mathrm{As}_{40} \mathrm{Se}_{60}$ and $\mathrm{Ge}_{17} \mathrm{As}_{18} \mathrm{Se}_{65}$ at 1,550 $\mathrm{nm}$ are $2.801 \pm 0.01$ and $2.590 \pm 0.01$, respectively (Lian et al. 2009). This refractive index difference is sufficient to provide designs that are robust against the small process-induced uncertainty in actual refractive index and has been demonstrated to remain at longer wavelengths, (Lian et al. 2009), which makes this pair suitable for forming high NA (numerical aperture) rib waveguides for near- and mid-IR applications. $\mathrm{T}_{\mathrm{g}}$ of the $\mathrm{Ge}_{17} \mathrm{As}_{18} \mathrm{Se}_{65}$ glass substrate is $236 \pm 2{ }^{\circ} \mathrm{C}$, which is higher than that of bulk $\mathrm{As}_{40} \mathrm{Se}_{60}$ glass: $178 \pm 2{ }^{\circ} \mathrm{C}$ (Pan et al. 2008). Thus moulding of the thermally deposited super-cooled thin film above $\mathrm{T}_{\mathrm{g}}$ took place within a range of temperatures for which the substrate was at higher viscosity than that of the thin film (Lian et al. 2009).

Han et al. (2010) have reported low-loss, smooth-walled, chalcogenide glass optical waveguides made via hot-embossing using a soft polydimethyl siloxane (PDMS) mould (comprising overclad./core/underclad. of air/ $\mathrm{As}_{24} \mathrm{~S}_{38} \mathrm{Se}_{38}$ /oxide-coated $\mathrm{Si}$; core: $2-5 \mu \mathrm{m}$ wide and $1 \mu \mathrm{m}$ high; optical loss: 0.26 and $0.27 \mathrm{~dB} \mathrm{~cm}^{-1}$ for the quasi-TM and quasiTE polarizations, respectively, at $1,550 \mathrm{~nm}$ ). However, it was reported later (Han et al. 2011) that the $\mathrm{As}_{24} \mathrm{~S}_{38} \mathrm{Se}_{38}$ glass used was actually susceptible to crystallization during the hot-embossing process (as well as exhibiting photosensitivity at 1,550 nm). To overcome these problems, thermally-evaporated $\mathrm{As}_{40} \mathrm{~S}_{60}$ films were given a protective $50 \mathrm{~nm}$ coating of thermally-evaporated $\mathrm{Ge}_{11.5} \mathrm{As}_{24} \mathrm{Se}_{64.5}$, prior to the application of the soft-mould hotembossing step, and this led to rib waveguides of good glass stability but of slightly higher reported optical loss, of $0.5 \mathrm{~dB} \mathrm{~cm}^{-1}$ at $1,550 \mathrm{~nm}$ (Han et al. 2011).

A record low waveguide optical loss of $0.05 \mathrm{~dB} \mathrm{~cm}^{-1}$ at $1,550 \mathrm{~nm}$ wavelength has been reported by the group of Luther-Davies (Madden et al. 2007) for the quasi-TE mode in 
$\mathrm{As}_{40} \mathrm{~S}_{60}$ waveguides up to $22.5 \mathrm{~cm}$ long. This was achieved not by hot-embossing but by using traditional photolithography and etching of thermally evaporated $\mathrm{As}_{40} \mathrm{~S}_{60}$ films on an oxidized silicon substrate. However, the chalcogenide glass was susceptible to attack by the alkaline-based developer used in the photolithographic procedure. This problem led to the successful introduction of protective layers applied to the thermally evaporated $\mathrm{As}_{2} \mathrm{~S}_{3}$ film prior to processing; however process complexity was thereby increased (Choi et al. 2011).

$\mathrm{Hu}$ et al. (2007a) have fabricated chalcogenide glass rib waveguides using CMOScompatible processing. A $400 \mathrm{~nm}$ chalcogenide film was thermally-evaporated onto an oxidized Si wafer, which had been prior-patterned with photoresist. Sonication in acetone lifted the photoresist beneath the undesired parts of the chalcogenide film, hence removing these; a second chalcogenide thermal deposition was made sequentially to produce rib waveguides (comprising: overclad./core/underclad.: air/ $\mathrm{Ge}_{23} \mathrm{Sb}_{7} \mathrm{Se}_{70}$ rib: $1.2 \mu \mathrm{m}$ wide and $100 \mathrm{~nm}$ high, sitting on a $400 \mathrm{~nm} \mathrm{Ge}_{23} \mathrm{Sb}_{7} \mathrm{Se}_{70}$ slab waveguide/oxide coated $\mathrm{Si}$ wafer; waveguide optical loss: $0.5 \mathrm{~dB} \mathrm{~cm}^{-1}$ at $1,550 \mathrm{~nm}$ ). In their later work (Hu et al. 2010), strip waveguides (800 $\mathrm{nm}$ wide, $400 \mathrm{~nm}$ deep) of thermally-evaporated $\mathrm{As}_{2} \mathrm{~S}_{3}$ were prepared by the same lift-off processing. These waveguides were subsequently reflowed, by heating above $T_{g}$, to smooth the waveguide surfaces and lower surface optical scattering. The reflow process lowered waveguide optical loss from $6 \mathrm{~dB} \mathrm{~cm}^{-1}$ to about half of that. Hu et al. (2007b) have also defined waveguides in thermally-evaporated chalcogenide glass films using traditional lithography followed by $\mathrm{SF}_{6}$ plasma etching (waveguides comprised: overclad./core/underclad. of air/400 nm thick $\mathrm{Ge}_{23} \mathrm{Sb}_{7} \mathrm{Se}_{70}$ film/oxidized $\mathrm{Si}$; waveguide optical loss: $2.3 \mathrm{~dB} \mathrm{~cm}^{-1}$ at $1,550 \mathrm{~nm}$ ). Interestingly, these latter waveguides have been used in conjunction with microfluidics as a near-IR evanescent sensor device to detect the $[\mathrm{N}-\mathrm{H}]$ vibrational absorption of $\mathrm{N}$-methylaniline (Hu et al. 2007b). Recently a wide range of compositions in the Te-Ge-Se ternary system was prepared by thermal co-evaporation, and optical rib waveguides based on these compositions were fabricated using laser lithography and ion beam etching and shown to have losses of $1.2 \pm 0.6 \mathrm{~dB} \mathrm{~cm}^{-1}$ at a wavelength of $1.55 \mu \mathrm{m}$ (Vigreux et al. 2013).

In this paper, we present hot embossing of rib waveguides for the first time in a radiofrequency (RF)-magnetron sputter-deposited $\mathrm{As}_{40} \mathrm{Se}_{60}$ glass thin film on a $\mathrm{Ge}_{17} \mathrm{As}_{18} \mathrm{Se}_{65}$ glass substrate. RF sputtering is a very common deposition technique for thin films. The target material is usually in disc form and the RF sputtering is usually performed in an $\mathrm{Ar}$ gas atmosphere through the application of RF $(13.56 \mathrm{GHz})$ power between the substrate and the target material in an evacuated chamber. Ar+ ions are generated to sputter off atoms from the target which are then transported and condensed on the surface of the substrate material. The use of RF sputtering to deposit chalcogenide glasses has been proposed by Ramachandran and Bishop (1999), Turnbull et al. (2003), Balan et al. (2004), Solmaz et al. (2008). It has been previously reported (Balan et al. 2004) that, unlike thermal evaporation, RF-sputtering can be responsible for the formation of column-like structures, detected using atomic force microscopy, in thin films of some chalcogenide systems that were deposited on unheated silicon and glass substrates. The refractive index of these films was also shown to decrease with the film thickness because of a change in the morphology (porosity) of the films with thickness (Balan et al. 2004). This columnar structure was explained by Balan et al. (2004) in terms of the influence of deposition conditions, and in particular the ratio of substrate temperature to thin film melting point (K) (Thornton 1974). Furthermore, Balan et al. (2004) have shown that in general, multicomponent chalcogenide sputtered films of $\sim 4 \mu \mathrm{m}$ depth exhibit clustered columns of approximate diameter $250 \mathrm{~nm}$ (confirmed by scanning electron microscopic (SEM) images), leading to a porosity estimated at $\sim 33 \%$ and a measured decrease in refractive index of $\sim 10 \%$ compared to $<1 \mu \mathrm{m}$ depth films. 
It is shown here that waveguide loss in the sputter-deposited thin film is lowered as compared to that of a hot-embossed monomode rib waveguide in a thermally-evaporated $\mathrm{As}_{40} \mathrm{Se}_{60}$ glass thin film on a $\mathrm{Ge}_{17} \mathrm{As}_{18} \mathrm{Se}_{65}$ glass substrate (Lian et al. 2009). The reasons for the lowered optical loss are explored. Both of these sets of waveguides exhibited excellent glass stability; the glass stability of chalcogenide glass waveguides in general is briefly discussed.

\section{Sample preparation}

A $\mathrm{Ge}_{17} \mathrm{As}_{18} \mathrm{Se}_{65}$ glass rod and $\mathrm{As}_{40} \mathrm{Se}_{60}$ boule, batched from $\geq 5 \mathrm{~N}$ purity elements, were melted in a rocking furnace, quenched in a liquid metal alloy bath and then annealed at their respective $T_{g}$. Circular optical substrates (thickness $2.5 \mathrm{~mm}$ diameter $10 \mathrm{~mm}$ ) were sliced from the $\mathrm{Ge}_{17} \mathrm{As}_{18} \mathrm{Se}_{65}$ glass rod; both sides of the samples were then ground parallel. The substrate face for sputtering deposition was then polished to a $0.25 \mu \mathrm{m}$ finish. Finally the discs were hot pressed at $275^{\circ} \mathrm{C}$ in an in-house built vacuum rig (Pan et al. 2008), between two precision aligned tungsten carbide plates (supplied from Opus Metrology Limited) with flatness of $0.08 \mu \mathrm{m}$ and surface finish of $0.009 \mu \mathrm{m}$, to ensure the substrate surfaces were flat and parallel. The same tungsten carbide plates were used to hot press the melted $\mathrm{As}_{40} \mathrm{Se}_{60}$ boule into an aluminium ring at $225^{\circ} \mathrm{C}$, under vacuum, to produce the sputter-target (thickness $5 \mathrm{~mm}$, diameter $50 \mathrm{~mm}$ ).

A 4,232 nm film of $\mathrm{As}_{40} \mathrm{Se}_{60}$ was sputtered (at $\sim 0.1 \mathrm{~nm} \mathrm{~s}^{-1}$ ) onto the $\mathrm{Ge}_{17} \mathrm{As}_{18} \mathrm{Se}_{65}$ substrates. The sputtering was performed in an Ar atmosphere with a chamber pressure of $0.67 \pm 0.01 \mathrm{~Pa}, \mathrm{RF}$ frequency of $13.56 \mathrm{MHz} \pm 0.005 \%$ and forward power of $100 \mathrm{~W}$, being supplied to the target at pulse repetition frequency of $1 \mathrm{kHz}$ and duty cycle of $25 \%$. The substrates were heated to $145^{\circ} \mathrm{C}$ in-situ while depositing in order to encourage adhesion between the substrates and the sputtered film.

The in-house built vacuum pressing rig, mentioned earlier, had two flat and parallel aluminium plates; the upper one was fixed and the lower one was raised to apply the force. A silicon wafer mould was placed on the lower plate with the patterned face facing up. The silicon wafer had been etched using inductively coupled plasma (ICP) to form a series of channels in the mould surface with a nominal depth of $2 \mu \mathrm{m}$, widths from $1 \mu \mathrm{m}$ to $10 \mu \mathrm{m}$, in steps of $0.5 \mu \mathrm{m}$ and centre-to-centre spacing of $50 \mu \mathrm{m}$. The chalcogenide glass sample was placed on top of the mould, with the sputtered film contacting the patterned mould surface. The temperature of both aluminium plates was raised to $215^{\circ} \mathrm{C}$ i.e. $\left[\mathrm{T}_{\mathrm{g} \text { (thin film) }}+30^{\circ} \mathrm{C}\right]$. Using a too high pressing temperature, for example $\left[\mathrm{T}_{\mathrm{g}(\text { thin }}\right.$ film) $\left.+60^{\circ} \mathrm{C}\right]$ was reported by Lian et al. (2009) to result in bubbles and holes in the sputtered film which in turn caused deformation and breakage of the embossed ribs' pattern. The lower aluminium plate was raised to accomplish the embossing. The temperature was then lowered from 215 to $205^{\circ} \mathrm{C}$ so as to increase the viscosity of the film and freeze the pattern of the super-cooled patterned film before releasing the applied load. The load was released and the glass sample was then annealed in situ at $\mathrm{T}_{\mathrm{g} \text { (thinfilm) }}$ (Table 1) and cooled to room temperature. The sample was then detached from the mould and, for optical assessment, mirror-like end faces were formed at the entrance and exit of the waveguides by means of brittle fracture achieved by cleaving using a diamond saw to cut first from the back of the sample then prising the cleave open using a $0.3 \mathrm{~mm}$ blade.

\section{Characterisation and results}

Figure 1a shows an environmental scanning electron microscope (ESEM) cross-sectional image of a cleaved edge of the as-sputtered $\mathrm{As}_{40} \mathrm{Se}_{60}$ film on a $\mathrm{Ge}_{17} \mathrm{As}_{18} \mathrm{Se}_{65}$ substrate 
Table 1 Experimental steps of hot-embossing process of RF-sputtered films of $\mathrm{As}_{40} \mathrm{Se}_{60}$ on a Ge${ }_{17} \mathrm{As}_{18} \mathrm{Se}_{65}$ bulk glass substrate

\begin{tabular}{|c|c|c|}
\hline Step & Procedure & Description \\
\hline 1 & $\begin{array}{l}\text { Increase temperature } \\
\text { from room temperature } \\
\text { (RT) to } 215^{\circ} \mathrm{C} \text { in } 1 \mathrm{~h}\end{array}$ & $\begin{array}{l}\text { Sample temperature } \\
\text { increased to } 30^{\circ} \mathrm{C} \\
\text { above the } \mathrm{T}_{\mathrm{g}} \text { of } \\
\mathrm{As}_{40} \mathrm{Se}_{60} \text { thin film }\end{array}$ \\
\hline 2 & Dwell at $215^{\circ} \mathrm{C}$ for $10 \mathrm{~min}$ & Thermal equilibration \\
\hline 3 & Apply force: $0-130 \mathrm{~N}$ in $5 \mathrm{~min}$ & Application of load \\
\hline 4 & Apply force of $130 \mathrm{~N}$ for $15 \mathrm{~min}$ & Patterning of the sputtered film \\
\hline 5 & Step temperature from $215^{\circ} \mathrm{C} \rightarrow 205^{\circ} \mathrm{C}$ & Freeze-in patterned ribs \\
\hline 6 & Release force suddenly & Removal of load \\
\hline 7 & Decrease temperature from 205 to $185^{\circ} \mathrm{C}$ in $30 \mathrm{~min}$ & Cool to $\mathrm{T}_{\mathrm{g}}$ of $\mathrm{As}_{40} \mathrm{Se}_{60}$ thin film \\
\hline 8 & Dwell $1 \mathrm{~h}$ & Annealing of the embossed sample \\
\hline 9 & Decrease temperature from 185 to $150^{\circ} \mathrm{C}$ at $5^{\circ} \mathrm{C} / \mathrm{h}$ & Cool to ambient \\
\hline 10 & Decrease temperature from $150^{\circ} \mathrm{C}$ to $\mathrm{RT}$ at $20^{\circ} \mathrm{C} / \mathrm{h}$ & \\
\hline
\end{tabular}

\section{(a)}

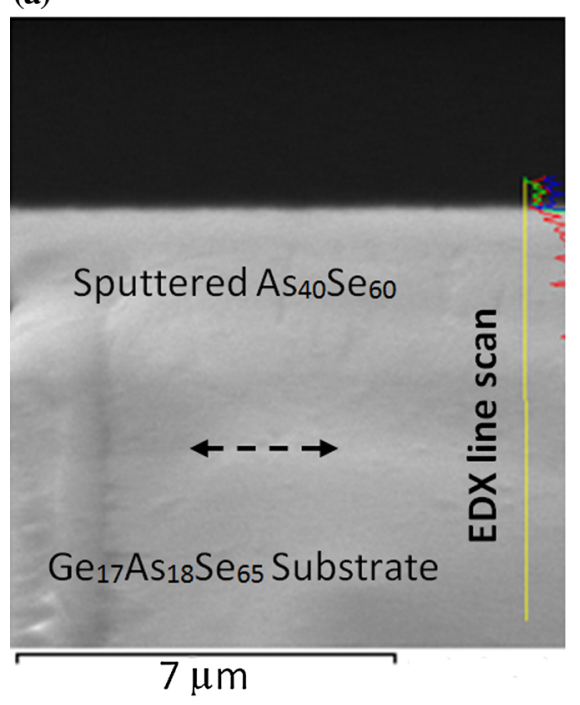

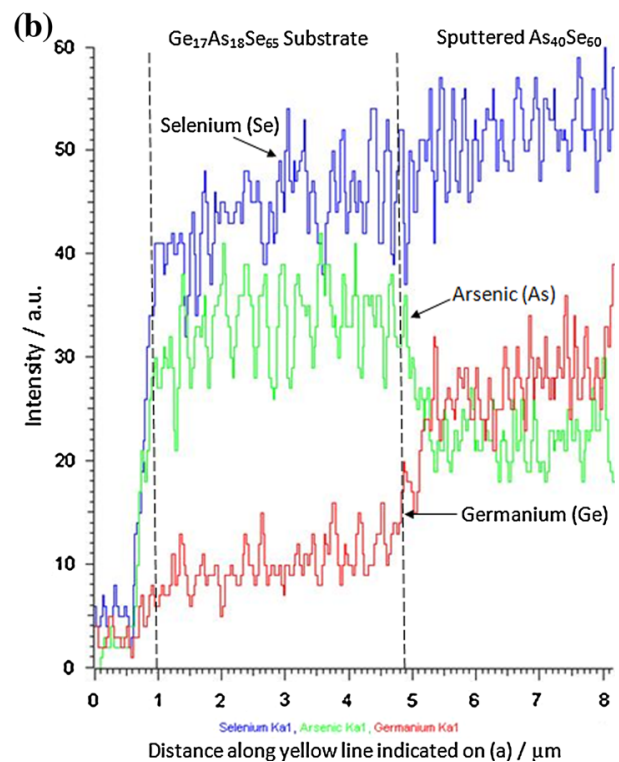

Fig. 1 a ESEM cross-sectional image of a cleaved edge of as-sputtered $\mathrm{As}_{40} \mathrm{Se}_{60}$ film on a $\mathrm{Ge}_{17} \mathrm{As}_{18} \mathrm{Se}_{65}$ substrate. The interface between the two chalcogenide compositions is not visible which indicates a defect free and well adhered interface. b Energy-dispersive X-ray spectroscopy (EDX) intensity for Ge, As and Se elements across the cleaved edge undertaken using the ESEM (XL30, FEG-ESEM). The position of the EDX intensity scans follow the vertical line indicated on a and is referenced to surface. The expected increase in Ge concentration observed at the thin film-substrate interface is accompanied by a corresponding decrease of As concentration

placed slightly off-centre from the sputter target The interface between the two chalcogenide compositions is not visible, which indicates a defect-free and well adhered interface. Energydispersive X-ray spectroscopy (EDX) for Ge, As and Se elements across the cleaved edge was undertaken using the ESEM (XL30, FEG-ESEM), Fig. 1b. In Fig. 1b the position of 

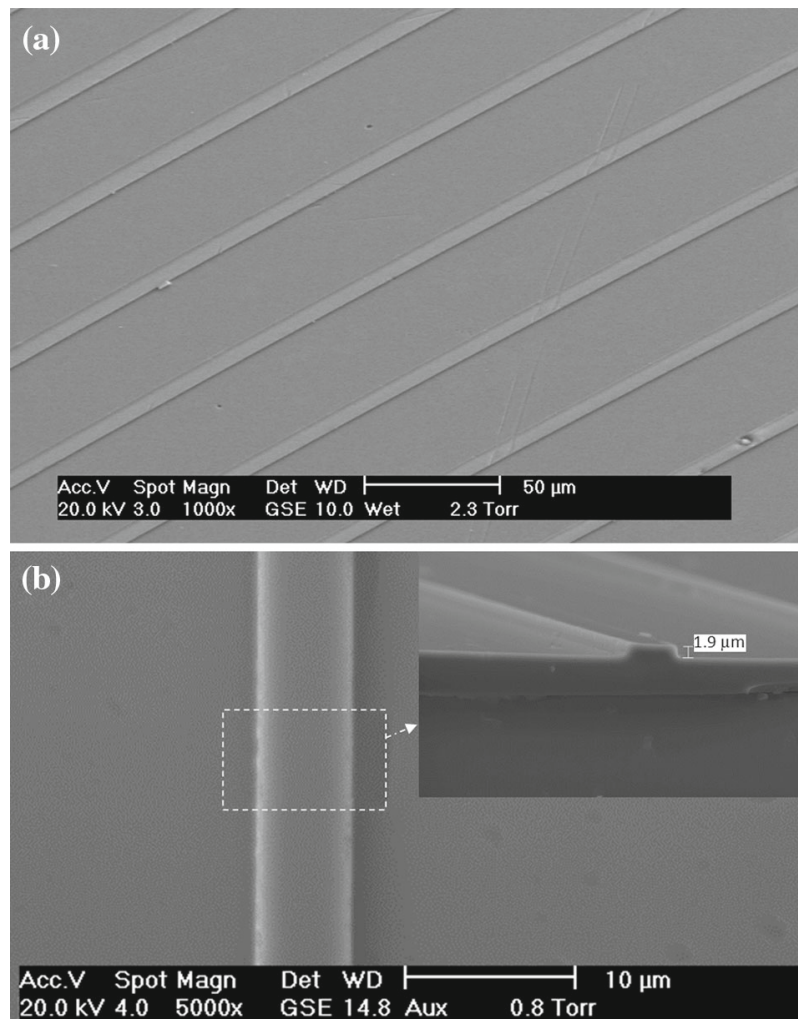

Fig. 2 SEM image of: a top view of $\mathrm{As}_{40} \mathrm{Se}_{60}$ glass ribs on $\mathrm{Ge}_{17} \mathrm{As}_{18} \mathrm{Se}_{65}$ glass substrate and $\mathbf{b}$ one of the ribs at higher magnification, with a cross-sectional view inset

the EDX intensity scans follow the vertical line indicated on Fig. 1a and is referenced to surface, through the sputtered film of $\mathrm{As}_{40} \mathrm{Se}_{60}$ to the $\mathrm{Ge}_{17} \mathrm{As}_{18} \mathrm{Se}_{65}$ substrate. The expected increase in Ge concentration observed at the thin film-substrate interface is accompanied by a corresponding decrease of As concentration. The ESEM image of the As $40 \mathrm{Se}_{60}$ cleaved film cross-section (Fig. 1a) appears smooth and no columnar growth through the cleaved crosssection is observed as previously found for more complex chalcogenide glass sputtered thin films of a similar $\sim 4 \mu \mathrm{m}$ depth by Balan et al. (2004).

Figure 2 shows Scanning Electron Microscope (SEM) images of typical rib waveguides formed. Amorphicity of the fabricated waveguides was demonstrated by means of X-ray diffraction.

A tapered silica glass fibre was used to end-fire couple a polarized 1,550 nm laser beam from a tuneable semiconductor laser (Agilent 81980A) into the end of a fabricated waveguides. The transmitted light from the waveguide was collected from the output end face using a $40 \times$ microscope objective; the near-field intensity pattern was imaged on a near-IR-sensitive camera and displayed on a television monitor. The television signal was also sampled electronically to quantify the near-field profile.

Figure 3a shows the quasi-single mode guided mode profile of the TE-like mode supported by a $6 \mathrm{~mm}$ long sample with a nominal rib width of $5 \mu \mathrm{m}$ and height of $1.9 \mu \mathrm{m}$, at wavelength $1,550 \mathrm{~nm}$. The corresponding horizontal line scan is also shown fitted to a Gaussian beam profile. The measured full-width-at-half-power of the near field image of this mode was 

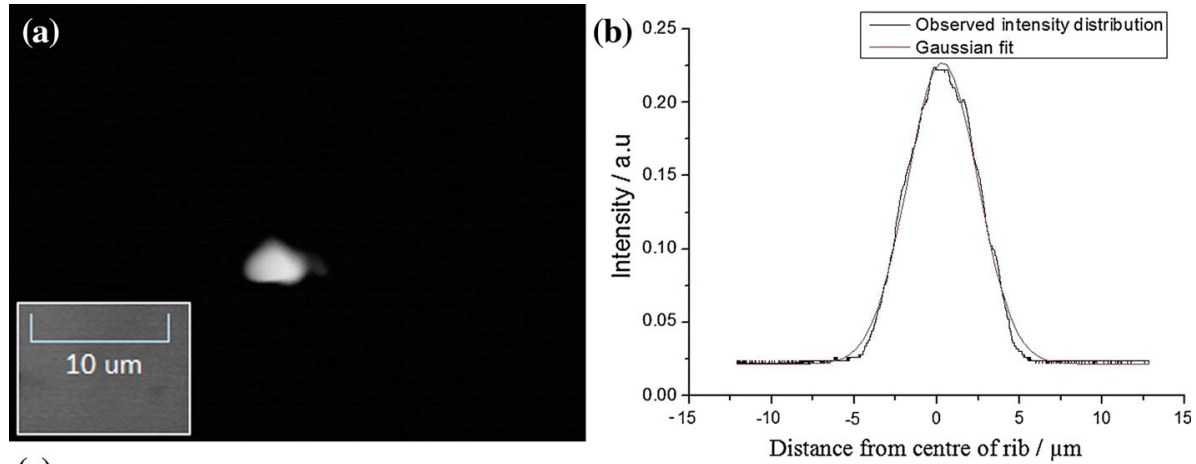

(c)

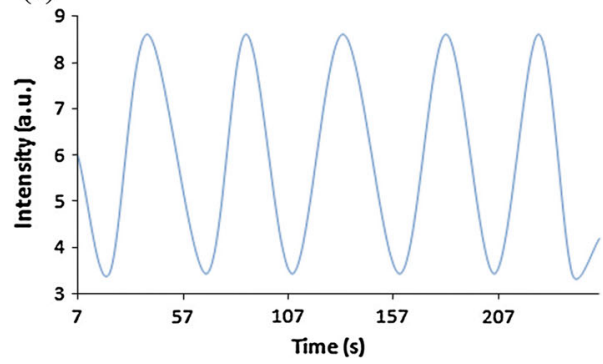

Fig. 3 a Near-field intensity profile observed at 1,550 nm wavelength, quasi-TE mode, b horizontal line scan at maximum intensity of the $5 \mu \mathrm{m}$ wide rib waveguide shown in a fitted to a Gaussian peak. c Fabry-Perot fringe pattern-output intensity plotted against time as the sample cooled after gentle heating

$5.2 \pm 0.1 \mu \mathrm{m}$, in agreement with numerical calculations. Similar mono-mode propagation was observed from several of the embossed ribs (widths between $4 \mu \mathrm{m}$ and $6 \mu \mathrm{m}$ ). This was also in agreement with Soref et al. (1991), and numerical calculations based on a semi-vectorial Finite Difference Method with sub-sampling of fine features (Wykes et al. 2005), similar to those reported for silicon-on-insulator waveguides by Lousteau et al. (2004). Material loss was not included in these calculations. Table 2 shows the simulated optical leakage loss of the fundamental, second and third order modes of the rib waveguides structures with nominal width between 4-6 $\mu \mathrm{m}$ wide and $1.9 \pm 0.1 \mu \mathrm{m}$ high that shows effective single mode behaviour in the quasi-TE and quasi-TM polarisations.

Propagation loss was measured using a Fabry-Perot resonance method (Walker 1985). A soldering iron heated at $200{ }^{\circ} \mathrm{C}$ was placed over the top of the guiding rib, non-contacting, to provide gentle heat, and then removed. The maximum and minimum intensities of the resulting Fabry-Perot resonances as the sample cooled were measured with the aid of a photodiode connected to a lock-in amplifier with an optical chopper providing a $150 \mathrm{~Hz}$ reference. Figure $3 \mathrm{c}$ shows a typical Fabry-Perot output intensity response as a function of time for the quasi-TE mode supported by the $5 \mu \mathrm{m}$ wide rib waveguide at $1,550 \mathrm{~nm}$ wavelength. The fringe contrast was highly repeatable over a period of 3 weeks showing no signs of waveguide degradation. The maximum propagation loss was evaluated to be less than $0.78 \pm 0.02 \mathrm{~dB} \mathrm{~cm}^{-1}$ for the quasi-TE mode and less than $0.81 \pm 0.1 \mathrm{~dB} \mathrm{~cm}^{-1}$ for the quasiTM mode at a wavelength of $1,550 \mathrm{~nm}$. The Fabry-Perot technique measures the round-trip loss inside the waveguide cavity. In order to obtain the waveguide loss the facet reflection contribution to cavity loss was (optimistically) taken as that numerically calculated for a perfect end-face. Due to the nature of the cleaving process, we expect there to be defects on the end- 
Table 2 Optical loss of the fundamental, second and third order modes supported by the rib waveguides structure 4-6 and $2 \mu \mathrm{m}$ high simulated using the Finite Difference Method for the quasi-TE and quasi-TM polarisations

\begin{tabular}{|c|c|c|c|c|c|c|}
\hline \multirow{3}{*}{$\begin{array}{l}\text { Rib width } \\
(\mu \mathrm{m})\end{array}$} & \multicolumn{6}{|c|}{ Loss $/ \mathrm{dB} \mathrm{cm}^{-1}$} \\
\hline & \multicolumn{2}{|c|}{ Fundamental mode } & \multicolumn{2}{|l|}{ 2nd order } & \multicolumn{2}{|l|}{ 3rd order } \\
\hline & $\begin{array}{l}\text { Quasi-TE } \\
\text { mode }\end{array}$ & $\begin{array}{l}\text { Quasi-TM } \\
\text { mode }\end{array}$ & $\begin{array}{l}\text { Quasi-TE } \\
\text { mode }\end{array}$ & $\begin{array}{l}\text { Quasi-TM } \\
\text { mode }\end{array}$ & $\begin{array}{l}\text { Quasi-TM } \\
\text { mode }\end{array}$ & $\begin{array}{l}\text { Quasi-TM } \\
\text { mode }\end{array}$ \\
\hline 4.0 & $8.91 \times 10^{-4}$ & $9.51 \times 10^{-4}$ & 38.3 & 39.8 & 72.4 & 72.6 \\
\hline 4.5 & $5.66 \times 10^{-4}$ & $6.27 \times 10^{-4}$ & 32.4 & 35.2 & 67.4 & 70.2 \\
\hline 5.0 & $1.31 \times 10^{-4}$ & $2.01 \times 10^{-4}$ & 29.5 & 32.5 & 65.7 & 68.6 \\
\hline 5.5 & $8.32 \times 10^{-4}$ & $8.88 \times 10^{-4}$ & 27.7 & 30.1 & 62.2 & 64.7 \\
\hline 6.0 & $5.64 \times 10^{-4}$ & $6.30 \times 10^{-4}$ & 26.8 & 27.9 & 58.8 & 59.7 \\
\hline
\end{tabular}

faces of the waveguides so cleaved and hence the end-face modal reflectivity to be lower than this numerical value. Therefore, waveguide loss will be lower than the values stated above.

\section{Discussion}

Here, the optical loss of a hot-embossed rib waveguide in a RF-magnetron sputter-deposited $\mathrm{As}_{40} \mathrm{Se}_{60}$ glass thin film on a $\mathrm{Ge}_{17} \mathrm{As}_{18} \mathrm{Se}_{65}$ glass substrate has been demonstrated to be lower than the optical loss found in the earlier work of Lian et al. (2009) who studied a hotembossed mono-mode rib waveguide in a thermally-evaporated $\mathrm{As}_{40} \mathrm{Se}_{60}$ glass thin film, on a similar $\mathrm{Ge}_{17} \mathrm{As}_{18} \mathrm{Se}_{65}$ glass substrate. The lower loss is suggested due to greater density and homogeneity of the chalcogenide glass films produced by RF-sputtering compared to those produced by thermally-evaporation. Lian et al. (2009) and Lian (2010) reported a change of $>0.1$ in the refractive index of thermally evaporated $\mathrm{As}_{40} \mathrm{Se}_{60}$ films compared to that of $\mathrm{As}_{40} \mathrm{Se}_{60}$ bulk glass. This was explained by the non-accurate transfer of the stoichiometric percentage of As and Se between the bulk target and the thermally evaporated films which agrees with the explanation of Zakery and Elliott (2007) that the thermal evaporation method is not suitable to transfer the accurate stoichiometry of multi-component glass films. The results in Lian et al. (2009) and Lian (2010) also showed that the refractive index of the hot embossed, thermally-evaporated $\mathrm{As}_{40} \mathrm{Se}_{60}$ film was closer to that of the bulk glass. Moreover, excellent glass stability and waveguide stability, with time stored under ambient conditions, has been found not only for the waveguides reported here for the first time, but also for the waveguides originally reported (Lian et al. 2009) that were hot-embossed in thermallyevaporated $\mathrm{A}_{40} \mathrm{Se}_{60}$ thin films.

This observed glass and rib-waveguide stability is in stark contrast to the results of some others for chalcogenide glass rib waveguides. Thus the group of Luther-Davies has reported post-processing problems of crystallization of $\mathrm{As}_{40} \mathrm{~S}_{60}$ rib waveguides which had been formed in thermally-evaporated $\mathrm{As}_{40} \mathrm{~S}_{60}$ films on a substrate of oxidized $\mathrm{Si}$. This crystallization occurred whether the waveguide ribs were formed by hot-embossing using a soft PDMS mould or were formed using the standard photolithographic and etching type of processing (Choi et al. 2011). In addition, Hu et al. (2008) reported that they coated thermally-evaporated $\mathrm{As}_{40} \mathrm{~S}_{60}$ with SU8 polymer to "prevent surface oxidation of devices in $\mathrm{As}_{40} \mathrm{~S}_{60}$ ". Moreover, (Hu et al. 2010) post-heat-treated waveguides at $140^{\circ} \mathrm{C} / 3 \mathrm{~h}$ to "stabilize the glass structure". Yet no such problems were reported when they applied similar processing to form $\mathrm{Ge}-\mathrm{Sb}-\mathrm{S}$ 
rib waveguides, in which, purposefully, no additional upper cladding layer was added $(\mathrm{Hu}$ et al. 2007a, b). Others have also advocated SU8, and $\mathrm{Al}_{2} \mathrm{O}_{3}$, coatings to protect $\mathrm{As}_{40} \mathrm{~S}_{60}$ thermally-evaporated films during processing and post-processing "to prevent the oxidation of $\mathrm{As}_{40} \mathrm{~S}_{60}$ " (Choi et al. 2011) and, similar to Hu et al. (2010) employed a heat-treatment at $130^{\circ} \mathrm{C} / 24 \mathrm{~h}$ in a vacuum oven (Choi et al. 2011). As an alternative explanation to crystallization by surface photo-oxidation of $\mathrm{As}_{40} \mathrm{~S}_{60}$ rib waveguides, formed in thermally-evaporated $\mathrm{As}_{40} \mathrm{~S}_{60}$ films, Wang et al. (2006) have referred to a type of intrinsic phase separation in $\mathrm{As}_{40} \mathrm{~S}_{60}$ to explain crystallization of pulsed laser deposited films of $\mathrm{As}_{40} \mathrm{~S}_{60}$, and this intrinsic phase separation is suggested to be present even in $\mathrm{As}_{40} \mathrm{~S}_{60}$ bulk glass itself, according to the ideas of Georgie et al. (2003), but these ideas are not universally accepted. As eloquently reviewed by Nordman et al. (1998), what is generally accepted is that thermally-evaporated $\mathrm{As}_{40} \mathrm{~S}_{60}$ films inevitably contain the molecular clusters, composed of both hetero-polar bonds and homo-polar 'wrong' bonds, found in the vapour state itself, and that heat-treating can help to lower the prevalence of the 'wrong bonds' and also densify thermally-evaporated films to achieve more nearly the same refractive index as that of the parent bulk-glass.

From the above studies, it might be concluded that it is the thermal-evaporation process that is problematic and that RF-sputtering might lead to more robust glass films. Against this are: (i) our results that hot-embossing rib waveguides in thermally-evaporated $\mathrm{As}_{40} \mathrm{Se}_{60}$ films were stable with time and (ii) Solmaz et al. (2008) found that RF-sputtered films of As $40 \mathrm{Se}_{60}$ which were initially smooth and featureless directly after hot-embossing under a hard mould, crystallized within the first few hours under ambient conditions; but their mould had been coated with an organic molecular surfactant, which may have degraded under the action of the heat during their hot-embossing and contaminated and reacted with the chalcogenide film being hot-embossed.

Apart from the work of Solmaz et al. (2008), the commonality between waveguides suffering post-processing crystallization is that: (i) all are formed in thermally-evaporated $\mathrm{As}_{40} \mathrm{~S}_{60}$-based films and (ii) these films all appear to have been deposited on a substrate of oxidized Si. Whereas in our work, rib waveguides stable to crystallization have been hotembossed in either thermally-evaporated $\mathrm{As}_{40} \mathrm{Se}_{60}$ films or RF-sputtered $\mathrm{As}_{40} \mathrm{Se}_{60}$ films, on a multicomponent chalcogenide glass substrate.

Our next step is to apply this process to larger scale wafers. Also our recent electromagnetic wave modelling has showed that the fabricated waveguides can also be expected to have low optical loss at operating wavelengths between 4 and $5 \mu \mathrm{m}$. This increases the possibility for potential applications in the mid-infrared range such as biomedical sensing (Seddon 2011).

Open Access This article is distributed under the terms of the Creative Commons Attribution License which permits any use, distribution, and reproduction in any medium, provided the original author(s) and the source are credited.

\section{References}

Balan, V., Vigreux, C., Pradel, A.: Chalcogenide thin films deposited by radio-frequency sputtering. J. Optoelectron. Adv. Mater. 6(3), 875-882 (2004)

Choi, D.-Y., Madden, S., Bulla, D., Rode, A., Wang, R., Luther-Davies, B.: SU-8 protective layer in photo-resist patterning on $\mathrm{As}_{2} \mathrm{~S}_{3}$ film. Phys. Status Solidi C8(11-12), 3183-3186 (2011)

Georgie, D.G., Boolchand, P., Jackson, K.A.: Intrinsic nanoscale phase separation of bulk $\mathrm{As}_{2} \mathrm{~S}_{3}$ glass. Philos. Mag. 83(25), 2941-2953 (2003)

Han, T., Madden, S., Bulla, D., Luther-Davies, B.: Low loss chalcogenide glass waveguides by thermal nanoimprint lithography. Opt. Express 18(18), 19286-19291 (2010) 
Han, T., Madden, S., Debbarma, S., Luther-Davies, B.: Improved method for hot embossing $\mathrm{As}_{2} \mathrm{~S}_{3}$ waveguides employing a thermally stable chalcogenide coating. Opt. Express 19(25), 25447-25453 (2011)

Hu, J., Tarasov, V., Carlie, N., Feng, N.-N., Petit, L., Agarwal, A., Richardson, K., Kimerling, L.: Si-CMOScompatible lift-off fabrication of low-loss planar chalcogenide waveguides. Opt. Express 15(19), 1179811807 (2007a)

Hu, J., Tarasov, V., Agarwal, A., Kimerling, L., Carlie, N., Petit, L., Richardson, K.: Fabrication and testing of planar chalcogenide waveguide integrated microfluidic sensor. Opt. Express 15(5), 2307-2313 (2007b)

Hu, J., Carlie, N., Feng, N.-N., Petit, L., Agarwal, A., Richardson, K., Kimerling, L.: Planar waveguide-coupled, high-index-contrast, high-Q resonators in chalcogenide glass for sensing. Opt. Lett. 33(21), 2500-2502 (2008)

Hu, J., Feng, N.-N., Carlie, N., Petit, L., Agarwal, A., Richardson, K., Kimerling, L.: Optical loss reduction in high-index-contrast chalcogenide glass waveguides via thermal reflow. Opt. Express 18(2), 1469-1478 (2010)

Lousteau, J., Furniss, D., Seddon, A.B., Benson, T.M., Vukovic, A., Sewell, P.: The single mode condition for silicon-on-insulator optical rib waveguides with large cross-section. J. Lightw. Technol. 22(8), 1923-1929 (2004)

Lian, Z.G., Pan, W.J., Furniss, D., Benson, T.M., Seddon, A.B., Kohoutek, T., Orava, J., Wagner, T.: Embossing of chalcogenide glasses: monomode rib optical waveguides in evaporated thin film. Opt. Lett. 34(8), 12341236 (2009)

Lian, Z.G.: Fabrication of rib waveguides and optical fibres in chalcogenide glasses. Ph.D. thesis, University of Nottingham (2010)

Madden, S.J., Choi, D.-Y., Bulla, D.A., Rode, A.V., Luther-Davies, B., Ta'eed, V.G., Pelusi, M.D., Eggleton, B.J.: Long, low loss etched $\mathrm{As}_{2} \mathrm{~S}_{3}$ chalcogenide waveguides for all-optical signal regeneration. Opt. Express 15(22), 14414-14421 (2007)

Nordman, O., Nordman, N., Peyghambarian, N.: Electron beam induced changes in refractive index and film thickness of amorphous $\mathrm{As}_{\mathrm{X}} \mathrm{S}_{100-\mathrm{X}}$ and $\mathrm{As}_{\mathrm{X}} \mathrm{Se}_{100-\mathrm{X}}$ films. J. Appl. Phys. 84(11), 6055-6058 (1998)

Pan, W.J., Furniss, D., Rowe, H., Loni, A., Sewell, P., Benson, T.M., Seddon, A.B.: Fine embossing of chalcogenide glasses: first time submicron definition of surface embossed features. J. Non-Cryst. Solids 353(13-15), 1302-1306 (2007)

Pan, W.J., Rowe, H., Zhang, D., Zhang, Y., Loni, A., Furniss, D., Sewell, P., Benson, T.M., Seddon, A.B.: One-step hot embossing of optical rib waveguides in chalcogenide glasses. Microw. Opt. Technol. Lett. 50(7), 1961-1963 (2008)

Ramachandran, S., Bishop, S.G.: Low loss photoinduced waveguides in rapid thermally annealed films of chalcogenide glasses. Appl. Phys. Lett. 74(1), 13-15 (1999)

Seddon, A.B.: Chalcogenide glasses: a review of their preparation, properties and applications. J. Non-Cryst. Solids 184, 44-50 (2005)

Seddon, A.B., Pan, W.J., Furniss, D., Miller, C.A., Rowe, H., Zhang, D., McBrearty, E., Zhang, Y., Loni, A., Sewell, P., Benson, T.M.: Fine embossing of chalcogenide glasses-a new fabrication route for photonic integrated circuits. J. Non-Cryst. Solids 352, 2515-2520 (2006)

Seddon, A.B.: A prospective for new mid-infrared medical endoscopy using chalcogenide glasses. Int. J. Appl. Glass Sci. 2(3), 177-191 (2011)

Solmaz, M., Park, H., Madsen, C.K., Cheng, X.: Patterning chalcogenide glass by direct resist-free thermal nanoimprint. J. Vac. Sci. Technol. B26(2), 606-610 (2008)

Soref, R.A., Schmidtchen, J., Petermann, K.: Large single-mode rib waveguides in GeSi-Si and Si-on-SiO2. IEEE J. Quantum Electron. 27, 1971-1974 (1991)

Thornton, J.A.: Influence of apparatus geometry and deposition conditions on the structure and topology of thick sputtered coatings. J. Vac. Sci. Technol. 11(4), 666-670 (1974)

Tsay, C., Mujagić, E., Madsen, C.K., Gmachl, C.F., Arnold, C.B.: Mid-infrared characterization of solution processed $\mathrm{As}_{2} \mathrm{~S}_{3}$ chalcogenide glass waveguides. Opt. Express 18(15), 15523-15530 (2010)

Turnbull, D.A., Sanghera, J.S., Nguyen, V.Q., Aggarwal, I.D.: Fabrication of waveguides in sputtered films of GeAsSe glass via photodarkening with above bandgap light. Mater. Lett. 58, 51-54 (2003)

Vigreux, C., Vu Thi, M., Maulion, G., Kribich, R., Pradel, A.: Te-Ge-Se thermally co-evaporated films: elaboration, characterization, and use for the manufacture of IR rib waveguides, basic elements of $\mathrm{CO}_{2}$ microsensors. In: Proceedings 15th International Conference on Transparent Optical Networks (ICTON 2013), Paper TuD6.1 (2013)

Walker, R.G.: Simple and accurate loss measurement technique for semiconductor optical waveguides. Electron. Lett. 21, 581-583 (1985)

Wang, R.P., Madden, S.J., Zha, C.J., Rode, A.V., Luther-Davies, B.: Annealing induced phase transformations in amorphous $\mathrm{As}_{2} \mathrm{~S}_{3}$ films. J. Appl. Phys. 100, 0635241-0635244 (2006) 
Wykes, J.G., Sewell, P., Vukovic, A., Benson, T.M.: Subsampling of fine features in finite difference simulations. Microw. Opt. Technol. Lett. 44(1), 95-101 (2005)

Zakery, A., Elliott, S.R.: Optical Nonlinearities in Chalcogenide Glasses and their Applications. Springer, Berlin (2007) 